\title{
Grupo focal em pesquisa qualitativa sobre leitura com jovens
}

\section{Focus groups in qualitative research about reading with youths}

\author{
Márcia Cabral da Silva ${ }^{1}$
}

\begin{abstract}
RESUMO
Este artigo trata de uma experiência em pesquisa qualitativa sobre leitura com jovens na área da Educação, utilizando-se como método de coleta de dados o grupo focal. O método foi descrito e analisado à luz da abordagem sócio-histórica da linguagem. Além disso, o texto discute os desafios e as reflexões éticas em relação à utilização do método.
\end{abstract}

Palavras-chave: grupo focal; linguagem; abordagem sócio-histórica; jovens.

\begin{abstract}
This paper describes a qualitative research about reading with youths in the educational fields using focus groups methodology. The concept of focus groups was described and analyzed in the light of the social historical perspective of language. Furthermore, this text discusses the challenges and the ethical concerns regarding this methodology.
\end{abstract}

Keywords: focus groups; language; social and historical perspective; youths.

${ }^{1}$ Doutora em Teoria e História Literária pela Universidade Estadual de Campinas (UNICAMP), professora adjunta da Faculdade de Educação da Universidade do Estado do Rio de Janeiro e do Programa de Pós-graduação em Educação. Coordena o grupo de pesquisa "Infância, Juventude, Leitura, Escrita e Educação" na mesma instituição. A pesquisa em exame foi realizada no período entre 2007 e 2009 e contou com o apoio do Conselho Nacional de Ensino e Pesquisa $(\mathrm{CNPq})$ e da Fundação de Apoio à Pesquisa do Estado do Rio de Janeiro (FAPERJ), Brasil. Colaboração dos pesquisadores de iniciação científica: Ana Carolina Siqueira Veloso, Rodrigo Ruan Merat Moreno, Gisele Gonçalves Isaias e Déborah de Paula Areias. E-mail: marciacs@ism.com.br 
Este estudo enfatiza a metodologia do grupo focal no desenvolvimento da pesquisa "A Leitura do Jovem: Concepções e Práticas". Trata-se de pesquisa no âmbito de um curso de graduação em Pedagogia de uma universidade pública realizada com jovens em uma escola pública de formação de professores, no bairro do Jardim Botânico, zona sul da cidade do Rio de Janeiro.

A pesquisa desenvolveu-se em duas etapas. $\mathrm{Na}$ fase exploratória, com vistas ao levantamento preliminar de alguns dados, como o perfil cultural do grupo de alunos e o contexto social de origem dos entrevistados, optou-se pela aplicação de um questionário organizado em quatro campos: socioeconômico, trajetória escolar, campo sociocultural e trajetória de leitura. Como adverte Meksenas (2002), esse instrumento pode ser considerado um meio de "explorar opiniões ou contextos de vida que servirão à organização de futuras pesquisas qualitativas" (p. 134-135).

Na segunda etapa do estudo, verificou-se a necessidade de ampliação da metodologia inicial. Com essa finalidade, selecionou-se o grupo focal. Conforme assinalam Gatti (2005), Carey (1994) e Morgan (1997), a metodologia designada como grupo focal vem crescendo em diversas áreas, como da saúde, de marketing, da publicidade, da administração e gestão e, mais recentemente, nas pesquisas em Ciências Humanas. Diferentemente de outras técnicas, como a entrevista, por exemplo, possibilitaria a condução menos diretiva por parte dos pesquisadores e maior integração entre os participantes.

Todavia, a compreensão sublinhada tem sido objeto de grande polêmica entre os cientistas sociais. Segundo Gatti (2005), haveria uma tendência em tratar o grupo focal desde uma perspectiva baseada na entrevista coletiva (com procedimentos mais estruturados, tais como perguntas e questões mais controladas) até uma tendência que privilegiaria a rede de interações. Por esse ângulo, embora se considerem os temas-chave a serem examinados, haveria a possibilidade de trocas e a constituição de um campo emergente mais interativo entre os participantes. A orientação adotada neste trabalho assume esta última tendência e, com o intuito de redimensioná-la, estabelece interlocuções com a abordagem sócio-histórica presente em estudos sobre linguagem do pesquisador russo Mikhail Bakhtin².

${ }^{2}$ Embora o autor tenha refletido sobre tantas outras áreas de estudo, como a Literatura, a Estética, a Psicologia, por exemplo, nos limites deste trabalho será abordada, em especial, a investigação sobre a linguagem e os processos interativos. Cf: BAKHTIN, M. Marxismo e filosofia da linguagem. São Paulo: Hucitec, 1992; BAKHTIN, M. Estética da criação verbal. São Paulo: Martins Fontes, 1996, BAKHTIN, M. O freudismo. São Paulo: Perspectiva, 2004. 
A pesquisa em Ciências Humanas requer uma compreensão ética e política dos sujeitos nela envolvidos ${ }^{3}$. Nessa perspectiva, a pesquisa de base sócio-histórica, ancorada em alguns estudos de Mikhail Bakhtin (1992), pode indicar orientações frutíferas.

Uma primeira dimensão diz respeito à linguagem como espaço interativo, materializado em discursos e enunciados em processo de transformação constante. Tal espaço ganha vida à medida que os sujeitos do discurso agem uns sobre os outros e sobre a própria linguagem em contextos socioculturais e históricos específicos. Nas palavras de Bakhtin: "só a corrente da comunicação verbal fornece à palavra a luz da sua significação" (1992, p. 138).

Necessário sublinhar uma segunda dimensão, que também se refere aos estudos da linguagem - a esfera da compreensão do próprio discurso e do discurso alheio - impulsionada pelo caráter dialógico de toda enunciação verbal. Ou seja, segundo Bakhtin (1992), toda palavra provém de um locutor e é sempre dirigida a um ouvinte. Infere-se, a partir da assertiva indicada, que os enunciados carregam, de modo indissociável, o gérmen da sua resposta. Com efeito, residiria na perspectiva salientada o caráter dialógico de toda enunciação verbal.

Reitera-se, de tal modo, a necessidade de circunscrever a dimensão da linguagem à teoria sócio-histórica, de modo a garantir a palavra dos pesquisadores. Trata-se, como se pôde acompanhar, de uma opção ética e política de conceber os sujeitos como locutores e interlocutores no desenvolvimento da pesquisa (entrevistador e entrevistado), na condição de coautores do processo e dos resultados alcançados. Os dados colhidos, nesse caso, são discursos e, por tal ângulo, só podem ser examinados em sua opacidade, recuperando-se os ditos e os não ditos, as hesitações (BAKHTIN, 1992), em uma palavra, a sua intrínseca condição contraditória.

Nas palavras de Mikhail Bakhtin, entende-se que:

$\mathrm{Na}$ realidade, não são palavras o que pronunciamos ou escutamos, mas verdades ou mentiras, coisas boas ou más, importantes ou triviais, agradáveis ou desagradáveis etc. A palavra está sempre carregada de um conteúdo ou de um sentido ideológico ou vivencial. É assim que

\footnotetext{
${ }^{3}$ Conferir, em particular, as pesquisas reunidas em livro, cujo enfoque assinala as Ciências Humanas, a pesquisa e o exame dos trabalhos de Mikhail Bakhtin. FREITAS, M.; JOBIM E SOUZA, S.; KRAMER, S. (Orgs.). Ciências humanas e pesquisa: leituras de Mikhail Bakhtin. São Paulo: Cortez, 2003. Além desse conjunto de ensaios, foram observadas metodologias qualitativas de pesquisa, em edições brasileiras, assinaladas por Oliveira (1998), Pádua (2002), Severino (2004) e Meksenas (2002).
} 
compreendemos as palavras e somente reagimos àquelas que despertam em nós ressonâncias ideológicas ou concernentes à vida. (BAKHTIN, 1992, p. 95).

\section{O grupo focal realizado e a centralidade das interações}

Laranja: E a aula de geografia, nem se fala! Só falava de arma [...]. (Todos falam juntos, concordando)

Lilás: Teve uma vez que ela deu aula de tiro! Como matar uma pessoa sem fazer ela sofrer... O que tem a ver com Geografia?

Verde: Vocês vão publicar isso lá, né? A nossa fala [....]. Porque, nossa, é uma vergonha a gente falar isso da nossa escola.

(Todos riem)

Verde: Não; é sério! A gente poderia tá falando muito bem, mas não tem condição, gente.

O quarto grupo focal ${ }^{4}$ realizado contou com a participação de quatro estudantes (três jovens moças e um jovem rapaz), todos cursando o terceiro ano, etapa anterior ao último ano do curso médio de formação de professores, além do moderador e três pesquisadores de iniciação científica. Embora houvesse algumas questões norteadoras da discussão $0^{5}$, a grande expectativa dos pesquisadores dizia respeito à possibilidade de compreender as perspectivas dos jovens para o exercício da docência, o que eles entendiam por leitura, quais as

${ }^{4}$ Foram realizados quatro grupos focais ao todo, com duração, em média, de 1 h30min. Para fins deste estudo, selecionei o quarto grupo, visto que os pesquisadores o consideraram o mais complexo, com muitos momentos de hesitação e de silêncio entre os participantes.

${ }^{5}$ Sugestão de roteiro: o conceito de juventude; diferenças no interior desse grupo social; atividades realizadas pelos jovens, o lugar da leitura em meio às atividades; o conceito de leitor; a leitura desenvolvida atualmente; o conceito de literatura; leituras relacionadas à literatura já desenvolvidas ou que estejam sendo desenvolvidas; relação entre literatura e imaginário: o enredo, o cenário, as ideias, os personagens, aspectos relacionados à materialidade da leitura: ilustração, projeto gráfico, qualidade do papel; tipos de leitura que circulam na escola; a importância desses tipos de leitura em sua vida; os tipos de leitura que circulam na família; mediadores da leitura no âmbito da família; modelo de leitor. 
práticas de leitura efetivamente desenvolvidas e, por fim, como essas práticas eram previstas relativamente ao exercício do magistério.

De início, solicitou-se que cada entrevistado escolhesse uma cor por meio da qual seria nomeado, de modo que a identificação não se constituísse em impedimento para a livre expressão. Registraram-se: laranja, verde, lilás e rosa.

Com o objetivo de motivá-los a participar da discussão, solicitou-se que cada um retirasse de uma caixa assuntos previamente selecionados, para comentar e instigar a discussão no grupo. Dentre os temas, destacam-se: escola, leitura, trabalho, futuro, cultura, biblioteca.

Moderador: Bom, então a gente vai começar este debate. Não precisa se preocupar porque não vai ser uma coisa chata, demorada, vai ser bem rápida. Então, quem pode...?

Verde: Nossa [...]. Olha só [...]

(Todos riem)

Moderador: Cada uma vai poder, assim... Vai falar o que pensa e os outros que acharem outra coisa podem falar. Quem vai começar? Verde?

O espaço interativo estabelecido por meio da linguagem, como indica Bakhtin (1992), não é constituído a priori e nem tampouco se trata de esfera consensual. Ao contrário, como o início do debate acima revela, a interação passa a ser estabelecida nas negociações de sentido, nas hesitações, nas entonações e até mesmo no riso, como espaço legítimo de produção de sentido, de construção social do lugar de onde o sujeito fala. Na situação acima referida, não se pode deixar de levar em conta os hierárquicos lugares discursivos que cada grupo ocupa: o dos pesquisadores, legitimados pela representação do saber que circula na universidade; o dos entrevistados, inseridos em instituição de ensino médio representada como de menor prestígio no sistema educacional.

Verde: Então, eu tirei a palavra escola e vou falar meu pensamento sobre escola? Bom, eu acho que a escola deveria ser um lugar onde a gente não tem que se preocupar com o que as pessoas sabem e sim [...] é $[. .$.$] com$ o que elas não sabem. Pra formular o pensamento, pra aumentar, né? É pra formar cidadões $(\mathrm{sic})$, pessoas de bem [...]. Hoje em dia não tem sido este o papel da escola, infelizmente. 
Moderador: E como é pensada a educação aqui no colégio? Como você avalia a educação?

Verde: Bom, aqui, né [...]? Como posso avaliar a escola. Em todos os níveis ou normal?

Moderador: Avalia do jeito que você achar melhor.

Verde: Ah, pela escola [...] a escola de curso normal parece ser uma fábrica de ilusão porque não tá formando professores. Tão formando assim [...] é [...] tão formando professores com diplomas, mas não estão formando professores aptos para o mercado de trabalho. Não saímos daqui com base. Muitos alunos pensam em sair daqui e ter que correr para um curso superior porque o ensino daqui não é [...]. Como é que eu posso dizer? Não é [...] não é bom!

Moderador: O que você acha que pode mudar?

Verde: Eu fiz prova para vir para cá, mas quando eu cheguei aqui eu tomei um susto!

Lilás: É verdade, a gente achou que por estar fazendo prova taria separando o joio do trigo, mas juntou tudo!

Verde: Chegou aqui, a gente viu isso aqui [...]

Lilás: A gente tem uma professora; ela escreveu shampoo com $\mathrm{CH} !$ !!

Verde: Com $\mathrm{CH}$ !

Lilás: Pelo amor de Deus, professora de português! Ela escreveu champoo. A gente falou: professora tá errado. E ela: Ah! Calma aí! Botou outro "o". Ficou com três Os: champooo. (Todos riem.)

Verde: Sério gente, tiraram até foto.

Ao se tentar compreender o modo como as interações se desenvolvem no grupo focal, chamam a atenção os níveis de autorização por meio dos quais os enunciados vão se estabelecendo no jogo de interlocução. De início, observa-se o entrevistado designado como Verde solicitando a autorização do moderador para enunciar: "E vou falar meu pensamento sobre escola?". Em meio às hesitações, passa do lugar de quem solicita autorização para a condição de autor, agente: o que produz enunciado, composto a partir de enfáticos comentários. Interpelado pelo moderador, retorna ao lugar de quem solicita permissão para 
enunciar: "Como posso avaliar a escola. Em todos os níveis ou normal?". Ainda na provisória condição de quem precisa de concessão, escuta por parte do moderador: "Avalia do jeito que você achar melhor". Outra vez, assumindo o lugar da autoria, ainda que hesite algumas vezes, examina, comenta e termina por sintetizar a sua apreciação de modo categórico: "o ensino daqui. Como eu posso dizer? Não é [...]; não é bom.”

Além da interação entre o moderador e um dos componentes do grupo, cabe sublinhar a ampliação do escopo das interações entre os demais membros. Como se pode ainda observar no fragmento acima, o membro designado por Lilás toma a palavra, sem solicitar autorização, tecendo avaliação severa tanto em relação à qualidade do ensino quanto à formação da professora de português. Nessa perspectiva, é válido afirmar que o jogo interativo deixa de ser exercido pelo locutor e interlocutor iniciais e começa a se estender para o grupo mais amplo, o grupo focal. Retomando-se os pressupostos teóricos já enunciados, observa-se que "a abertura do grupo é um momento crucial para a criação de condições favoráveis à participação de todos os componentes. Precisa-se criar uma situação de conforto, de certo distensionamento, para gerar uma atmosfera permissiva" (GATTI, 2005, p. 28). Os risos de todos ao final do segmento destacado acima parecem confirmar a hipótese referida.

\section{O moderador não ocupa um lugar neutro no jogo das interações}

O lugar do moderador, na condição de um dos participantes do grupo focal, tem sido considerado de modo bastante específico no desenvolvimento da metodologia do grupo focal. Como foi enfatizado de início, há o princípio da não diretividade como meio de garantir o foco nas interações entre os membros do grupo, afastando o entrevistador de um posicionamento mais controlador. Tal posicionamento surge, com frequência, por ocasião da utilização da entrevista de natureza individual ou coletiva, instrumento amplamente utilizado em pesquisas etnográficas (MEKSENAS, 2002; PÁDUA, 2004; SEVERINO, 2002). Em diálogo com os pressupostos traçados por Gatti (2005), atenta-se para o fato de que:

Na condução do grupo focal, é importante o respeito ao princípio da não diretividade, e o facilitador ou moderador da discussão deve cuidar para que o grupo desenvolva a comunicação sem ingerências indevidas da parte 
dele, como intervenções afirmativas ou negativas, emissão de opiniões particulares, conclusões ou outras formas de intervenção direta. Não se trata, contudo, de uma posição não diretiva absoluta, ou do tipo "laissezfaire”, por parte do moderador. Este deverá fazer encaminhamentos quanto ao tema e fazer intervenções que facilitem as trocas, como também procurar manter os objetivos de trabalho. (p. 8-9)

Todavia, o que parece se constituir um paradoxo - a interação pela linguagem entre os membros do grupo e o lugar discursivo menos diretivo do moderador - pode ser melhor compreendido se são levados em conta os pressupostos sócio-históricos da pesquisa em Ciências Humanas na direção de alguns princípios formulados por Bakhtin (1992; 1996).

A linguagem, esfera ideológica por excelência, ganha vida e materialidade a partir dos enunciados tecidos nas cadeias de interação verbal. Entender o desenvolvimento da pesquisa por esse ângulo implica dizer que há sempre dois ou mais sujeitos autores envolvidos porque são produtores de enunciados, de textos. Como já se observou inicialmente, os espaços criados pelas interações verbais são opacos e contraditórios, o que, de certo modo, confirma a posição de autoria de todos os participantes, incluindo-se o moderador.

A partir da perspectiva indicada, o moderador não poderia ocupar um lugar de neutralidade no jogo das interações. Observa-se, inclusive, a importância do seu enunciado como provocador de enunciados mais assertivos entre os participantes:

No curso do debate, tomando-se ainda como tema principal a escola relacionada ao trabalho dos professores, acompanha-se:

Moderador: E vocês vendo esses professores desse jeito, vocês querem ser professores?

Rosa: Queremos, mas não desse jeito!

Verde: Não desse jeito.

Moderador: Qual seria, então, o referencial de vocês?

Verde: Eu acho que a maioria tá, tá procurando até profissão diferente, né? Assim, a gente queria, assim, fazer também um curso de Pedagogia, mas aí o nosso professor também chegou falando, comentando, colocando o ponto de vista dele [...]. Dizendo que o curso de Pedagogia tá sendo uma fábrica de ilusão. Aí começou a passar o ponto de vista dele. Falou 
que as aulas de Pedagogia estão formando esquerdistas, pessoas que é contra esse negócio do dinheiro.

Laranja: É, e tem aquela professora lá, estagiária...

Verde: É, a professora falou também que as meninas da Pedagogia são bem $[\ldots]$ piranha!

Laranja: São fácil (sic).

Verde: Ela veio parecendo um professor de sexo, porque ela só falava de sexualidade.

Rosa: É, e tudo o que a gente falava sobre educação [...].

Todos: Ela era contra!

Verde: Ela era contra a educação. A concepção de escola dela era muito diferente. Eu também não entendi qual era.

Moderador: Mas só quem está lá dentro, fazendo a faculdade sabe o que é.

Verde: Não; desculpa. Vocês são de qual Faculdade mesmo? Não, ela é de outra, da Praia Vermelha.

(Silêncio).

Como se pode verificar, as interações verbais não ocorrem no vazio; há um contexto sócio-histórico e cultural atravessando os discursos e os constituindo. Deste ponto de vista, não é difícil compreender o tom de espanto por parte do moderador no início deste bloco de discussão - "E vocês vendo esses professores desse jeito, vocês querem ser professores?" - nem o pedido de desculpas por parte do jovem designado como Verde ao final do fragmento: "Não; desculpa. Vocês são de qual Faculdade mesmo? Não, ela é de outra, da Praia Vermelha.".

Em outras palavras, é necessário não perder de vista o lugar social que o moderador representa. Trata-se de um estudante do curso de Pedagogia que também está produzindo sentidos para os enunciados, para os assuntos selecionados. Ele também escolheu a docência como profissão. O lugar identificador que ocupa passa a se confrontar com os outros espaços de alteridade em vias de construção pelos alunos do Curso Médio de formação dos professores, em meio às representações da profissão docente enunciadas pelos demais professores da escola. Assim, de modo a capturar os sentidos em jogo no curso dessas 
interações, é necessário recuperar o tema do enunciado, como adverte Bakhtin, e o contexto para além das palavras.

Aliás, para Bakhtin (1992), o problema da significação é um dos mais complexos no campo dos estudos linguísticos, visto que o tema da enunciação estará sempre em jogo nas cadeias das interações verbais. Com o objetivo de explicitar o problema da significação, o autor discute exaustivamente as noções de tema e de significação. Segundo ele, o tema da enunciação é individual e não reiterável, pois determinado pelas condições históricas e sociais de produção do enunciado. Contudo, no interior do tema, subjaz a significação, que, diferentemente do tema, constitui os elementos reiteráveis e idênticos da enunciação cada vez que são produzidos. (BAKHTIN, 1992, p. 129).

Necessário, portanto, ter em conta o tema da enunciação em consonância com a noção de significação. Observem-se as palavras do autor, das quais emerge, na direção indicada, o conceito de compreensão ativa por parte do locutor e do interlocutor, por não perderem de vista os elementos enfatizados:

Compreender a enunciação de outrem significa orientar-se em relação a ela, encontrar o seu lugar adequado no contexto correspondente. A cada palavra da enunciação que estamos em processo de compreender, fazemos corresponder uma série de palavras nossas, formando uma réplica. Quanto mais numerosas e substanciais forem, mais profunda e real é a nossa compreensão. (BAKHTIN, 1992, p. 131-132).

Verifica-se, portanto, que, em relação aos processos interativos, o moderador tem um papel tão relevante quanto os demais integrantes do grupo focal. Na perspectiva assumida, não se trata de um lugar técnico de quem pode estar de fora. Ao contrário, sua função, tendo em conta os dados examinados, parece ser a de provocar um número significativo de réplicas - silenciosas ou materializadas em discursos - para o assunto investigado.

\section{Leitura, biblioteca e espaços de formação}

Em outro bloco, focalizou-se, em particular, a temática relacionada à leitura, com vistas a melhor compreender formas de apropriação das leituras realizadas, os espaços em que as práticas ocorrem na escola, além das formas de mediação entre os prováveis leitores e os suportes de leitura: 
Moderador: Qual a sua palavra?

Rosa: Caraca, o meu é leitura!

Verde: Ih, isso daí a gente tem demais! Aqui no curso normal, tá formando péssimos professores - não te cortando - por causa disso! A leitura aqui é péssima!A garota aqui não sabia escrever "trabalham"; ela escrevia "trabalhão". Aqui é péssima a parte de leitura! Olha a biblioteca! Só hoje que nós temos a oportunidade de tá aqui...

Lilás: Não [...] e quando vem, não pode!

Verde: Olha só os livros! Precário!! Não tem nenhum livro que fala de educação! Não tem nenhum livro que fala de juventude, se a gente quiser pegar, sentar, criar o hábito. Olha só como tá essa bagunça! Tá deplorável essa biblioteca! Tá suja!!

Moderador: O que você acha sobre leitura?

Rosa: Aqui no colégio?

Moderador: Em geral. No colégio, fora do colégio. Você é uma leitora?

Rosa: Não!

(Todos riem)

Verde: Não; fala que é sim, amiga! Você lê jornal, você lê fofoca, lê revista!

$\mathrm{Na}$ tentativa de construir significados para o assunto em tela, retorna-se à complexa questão da significação, já referida em análise anterior. Dada a relevância do assunto, convém ampliar a discussão. Se examinadas as diversas acepções da palavra leitura, como registradas em dicionário, seria válida a ênfase em sentidos tais como "ato ou efeito de decodificar signos gráficos, ação de tomar conhecimento de um texto escrito para se informar ou se distrair; o hábito ou gosto de ler; o que se lê", dentre outras.

Todavia, a significação atribuída pelos interlocutores em situação histórica e social determinada eleva a palavra do estado dicionarizável para cadeias de interações específicas. Na condição histórica em que ocorrem, as palavras materializadas em discursos precisam ser compreendidas como não reiteráveis. E a

\footnotetext{
${ }^{6}$ Conferir outras acepções no Dicionário Houaiss Eletrônico da Língua Portuguesa. 5.0 a.
} 
significação, por sua vez, torna-se possível porque se pode recuperar o contexto histórico das interações, em que estão em jogo também a apreciação em relação às palavras, a entonação, o conteúdo vivencial que adquirem, a possibilidade de réplicas e de contrapalavras. Esses elementos estarão presentes na perspectiva sócio-histórica relacionada à apreensão dos enunciados, como sublinha Bakhtin (1992). Verifica-se, portanto, a impossibilidade de entender a palavra "leitura", sorteada pelo entrevistado, fora do jogo das interações verbais, pois, segundo Bakhtin (1992):

[...] cada um dos elementos significativos isoláveis de uma enunciação e a enunciação toda são transferidos nas nossas mentes para um outro contexto, ativo e responsivo. A compreensão é uma forma de diálogo; ela está para a enunciação assim como uma réplica está para a outra no diálogo. Compreender é opor à palavra do locutor uma contrapalavra. (p. 132)

Ao se levar em consideração a orientação teórica formulada pelo pesquisador russo no contexto de seus estudos sobre linguagem, o conteúdo vivencial, histórico e social da palavra leitura focalizado no fragmento acima pode ser melhor examinado.

Merece destaque, de início, o fato de que o conceito de leitura no cenário da escola dos entrevistados exprime má-formação dos futuros professores, relação inadequada com a dimensão da palavra escrita, precariedade na manutenção dos livros e má conservação do espaço físico da biblioteca, no modo de percepção do entrevistado denominado como Verde: "Aqui no curso normal, está formando péssimos professores por causa disso [...]. Aqui a leitura é péssima". A este conjunto de noções histórica e socialmente determinadas, acrescente-se como réplica formulada pelo entrevistado designado por Lilás a noção de espaço interditado: "Não [...] e quando vem, não pode". Como se observa, a primeira interlocutora, denominada como Rosa, a quem o moderador dirigiu o seu enunciado, suscitou esse conjunto de significações para leitura a partir do seu tom de espanto, reforçado por uma expressiva palavra, marca identificadora dos enunciados dos jovens no espaço urbano do Rio de Janeiro: "Caraca, o meu é leitura".

Chama a atenção, da mesma forma, a intervenção do moderador para que a interlocutora Rosa retome a definição esperada tanto quanto as contrapalavras enunciadas por Rosa: 
Moderador: O que você acha sobre leitura?

Rosa: Aqui no colégio?

Moderador: Em geral. No colégio, fora do colégio. Você é uma leitora?

Rosa: Não!

Na perspectiva teórica anunciada, torna-se possível redimensionar o significado do conceito de leitura para os jovens em uma escola de formação de professores de nível médio, cuja experiência se encontra fortemente marcada pela ausência de investimento por parte do poder público e pela inadequação quanto ao acervo da biblioteca - com lacunas na área da educação e de assuntos relacionados à juventude. De tal modo, a palavra leitura eleva-se da condição dicionarizada, assumindo expressiva nuance vivencial, tanto em relação à percepção dos jovens entrevistados quanto ao moderador. De outra parte, a condição de não leitora assumida pela jovem Rosa pôde ser declarada, em contexto irônico e enfaticamente referido, porque a condição declarada passou a ser legitimada em confronto com os enunciados encadeados socialmente pelos demais interlocutores: “todos riem”. Verde: Não; fala que é sim, amiga! Você lê jornal, você lê fofoca, lê revista!

Em outro momento desse bloco de discussão, a entrevistada retoma as reflexões sobre a sua condição de leitora/não leitora, ao interagir com as contrapalavras e réplicas no interior do grupo focal:

Rosa: Tipo assim, eu não. Eu não fico lendo. Aliás, é um milagre! Tem que acontecer uma coisa assim, que chame muito a minha atenção pra eu ficar lendo! Aqui; eu tou com uma apostila pra ficar estudando pra prova. Sei lá, eu...

Moderador: Só lê por obrigação?

Rosa: Isso mesmo.

Todos: Que horror, que horror! (todos riem)

Rosa: Não me interessa, não! Mas tem que ser uma coisa que chame muito a minha atenção!

Moderador: A escola incentiva vocês em relação à leitura?

Rosa: Oi? 
Moderador: A escola incentiva?

Rosa: Não, acho que não.

Verde: Não, eu acho que incentiva! Tanto que entopem a gente de textos pra...

Todos: falam juntos (as palavras ficaram incompreensíveis para a transcrição)

Lilás: Porque os textos [...]. Eu acho que são muito ultrapassados. Nossa! Da época que o meu avô tinha cabelo!

Com vistas à compreensão do jogo interativo estabelecido no interior do grupo focal desta vez, convém destacar o forte tom de ironia entre os entrevistados. Observe-se que, nas interações destacadas acima, houve intervenções diretas por parte do moderador, ou seja, para cada questão categórica: "Só lê por obrigação?", “A escola incentiva vocês em relação à leitura?”, os jovens posicionavam-se assertivamente, ancorando-se, em grande parte, na entonação irônica: "Isso mesmo". "Que horror, que horror". "Todos riem". "Não, eu acho que incentiva! Tanto é que entopem a gente de textos pra..." "Da época que meu avô tinha cabelo".

Além do que já foi salientado a respeito dos efeitos de sentido produzidos pelas réplicas e contrapalavras, há de se acrescentar o jogo interativo que se estabelece por meio da entonação, dos não ditos e, tendo em vista a discussão sobre leitura incentivada pela escola, o elevado grau de ironia por parte dos jovens.

Por fim, no âmbito da pesquisa e da preparação prévia para a realização do grupo focal, indicou-se a importância da leitura em relação à prática docente como assunto a ser discutido com o grupo de jovens. Esta é a razão, portanto, para as interações que se seguem:

Moderador: Muitos de vocês querem ser professores. O governo sempre fala em leituras incentivadas. Como vocês vão incentivar a leitura sendo professores?

(Silêncio)

Lilás: Bom, eu acho que [...]. O bom foi como o Freinet fazia: os cantinhos de leitura. Eu acho muito interessante pras crianças. 
Verde: É mesmo.

Rosa: De vez em quando, tirar um horário, assim... Do seu tempo para fazer leituras com as crianças! Dar um livro. Mesmo que eles não saibam ler, mas para elas, assim, folhear o livro.

Lilás: Tipo assim, pelo menos lá no meu estágio, eles adoram ler! Adoram! Eu faço ali, no Humaitá! Eles adoram ler [...] de dois anos [...]. É difícil uma criança de dois anos sentar em uma rodinha e ficar sentado! Eles sentam! Ficam ali, ó [estala os dedos] com o livro.

No que diz respeito ao bloco relacionado ao exercício futuro da profissão docente, importa tanto destacar o tom de seriedade assumido nas interações quanto o silêncio inicial, o que parece marcar rupturas na produção de significados para os enunciados. Tal mudança anuncia lugar diferenciado para os jovens, talvez na condição de protagonistas em relação às práticas de leitura a serem efetivamente assumidas. De um lado, emerge a lembrança da leitura teórica com a qual tiveram contato ao longo da formação no ensino médio, como a relacionada ao educador Célestin Freinet, por exemplo, revela. De outro, destaca-se a rememoração da mediação com experiências de leitura vivenciadas em Estágio e Prática de Ensino e avaliadas positivamente. Em síntese, as significações no âmbito das interações modificam-se, conforme a ação dos sujeitos sobre a realidade e sobre os enunciados.

A título de conclusão, importa destacar que a fase de desenvolvimento da pesquisa em tela, descrita e analisada neste artigo, contribuiu para que os pesquisadores se apropriassem de modo mais efetivo da metodologia denominada grupo focal, explorando as diversas dimensões a ela relacionadas: organização do roteiro, seleção dos entrevistados, desenvolvimento do grupo focal, análise dos dados obtidos.

Todavia, não seria possível o exame dos espaços interativos construídos a partir da linguagem sem a adoção de uma perspectiva teórica que encarasse os autores da pesquisa na condição de sujeitos. A perspectiva sócio-histórica, aliada à utilização da metodologia grupo focal, permitiu não somente uma abordagem ética da pesquisa empreendida no âmbito das Ciências Humanas, como também a análise das interações como faceta da experiência de sujeitos em permanente processo de transformação. 


\section{REFERÊNCIAS}

BAKHTIN, Mikhail. Marxismo e filosofia da linguagem. São Paulo: Hucitec, 1992. . Estética da criação verbal. São Paulo: Martins Fontes, 1996.

. O freudismo. São Paulo: Perspectiva, 2004.

CAREY, Mark. A. The group effect in focus group: planning, implementing and interpreting focus group research. In: MORSE, M. (Org.). Critical issues in qualitative research methods. Thousand Oaks: Sage, 1994.

FREITAS, Maria Teresa; JOBIM E SOUZA, Solange; KRAMER, Sonia (Orgs.). Ciências humanas e pesquisa: leituras de Mikhail Bakhtin. São Paulo: Cortez, 2003.

GATTI, Bernadete Angelina. Grupo focal na pesquisa em ciências humanas. Brasília: Liber Livro, 2005.

HOUAISS DICIONÁRIO ELETRÔNICO DA LÍNGUA PORTUGUESA. São Paulo: Objetiva, 2005.

MEKSENAS, Paulo. Pesquisa social e ação pedagógica: conceitos, métodos e práticas. São Paulo: Edições Loyola, 2002.

MORGAN, David. Focus Groups as qualitative research. Newbury Park Ca: Sage Edition, 1997.

OLIVEIRA, Paulo de Salles (Org.). Caminhos de construção da pesquisa em ciências humanas. In: . Metodologia das ciências humanas. São Paulo: Hucitec/Unesp, 1998.

PÁDUA, Elisabete Matallo de. Sobre a questão do método. In: . Metodologia da pesquisa: abordagem teórico-prática. 10. ed. Campinas; São Paulo, 2004.

SEVERINO, Antônio Joaquim. Metodologia do trabalho cientifico. São Paulo: Cortez, 2002 .

Texto recebido em 27 de janeiro de 2010.

Texto aprovado em 15 de setembro de 2010. 